\title{
Evaluation of the degradation potential of different advanced oxidation processes for a textile dye mixture: a kinetic study with mathematical modeling and toxicological tests
}

\author{
Joanna Cysneiros Silva '; Rayany Magali da Rocha Santana II \\ Graziele Elisandra do Nascimento III ; Alex Leandro Andrade de Lucena IV \\ Ana Maria Ribeiro Bastos da Silva v ; José Luís Ferreira Sá vi \\ Ana Maria Mendonça de Albuquerque Melo VII ; Daniella Carla Napoleão VIII \\ Marta Maria Menezes Bezerra Duarte IX
}

\begin{abstract}
Studies and research have been developed around the world on environmental pollution. Among the most diverse types of pollutants, textile dyes have attracted attention in the Brazilian Northeast. These compounds, besides being persistent, resist to the conventional treatments applied in the wastewater treatment plants. Thus, the present study evaluated the degradation of the mixture of direct red 23, direct red 227 and direct orange 26 dyes by advanced oxidation processes (AOPs). It was observed that the homogeneous AOPs were more efficient, being able to degrade $100 \%$ of the chromophoric groups after the optimization of the variables [H2O2], [Fe] and $\mathrm{pH}$. The reaction kinetics for the photo-Fenton process followed a pseudo-first order non-linear model, with rapid decay of the concentrations in the first 60 min. Aiming to have a methodology capable of predicting the degradation efficiency for the studied processes, it was verified that the artificial neural networks MLP 4-9-3 and MLP 5-6-3 well represent the data from the homogeneous and heterogeneous processes, respectively. A toxicity study was carried out using seeds, bacteria and microcrustaceans and it was found that the intermediate compounds formed during the treatment process act differently for each of them.
\end{abstract}

Keywords: ANN; Descoloration; Photodegradation; Treatment

\footnotetext{
Universidade Federal de Pernambuco, Recife, Brazil. joannacysneiros@gmail.com

" Universidade Federal de Pernambuco, Recife, Brazil. rayanymagalirocha@gmail.com

II' Universidade Federal de Pernambuco, Recife, Brazil. grazielen@yahoo.com.br

Iv Universidade Federal de Pernambuco, Recife, Brazil. lucenaalex3@gmail.com

$\checkmark$ Universidade Federal de Pernambuco, Recife, Brazil. amrbsilva@ig.com.br

vı Universidade Federal de Pernambuco, Recife, Brazil. luismuma6@gmail.com

VII Universidade Federal de Pernambuco, Recife, Brazil. amdemelo@hotmail.com

VIII Universidade Federal de Pernambuco, Recife, Brazil. danicarlan@gmail.com

Ix Universidade Federal de Pernambuco, Recife, Brazil. mmmbduarte@gmail.com
} 


\section{INTRODUCTION}

The use of fabrics by humans dates back thousands of years. Due to the industrial advancement, and in order to provide distinct pieces with several different characteristics, a dyeing step was aggregated to the manufacturing process of these goods (Guaratini and Zanoni 2000). Due to the demands of the consumers, who want varied color fabrics, the number of textiles dyes available on the market has been increasing every day. However, the large use of dyes can generate problems, depending on the fiber fixing efficiency of the final products (Ghaly et al. 2014; Rawat et al. 2016).

The concern about the effluents generated by the textile industries has been reported in the literature for some decades, been related to the fact that a considerable amount of the dyes is not completely fixed and can cause pollution. This is easily noticeable to the human eye, even when present in low concentrations. The inappropriate disposal of these effluents can lead to a color change of the receptor bodies, affecting the photosynthetic metabolism of the medium and making it difficult to the solar rays to penetrate (Hisaindee et al. 2013).

Once the presence of coloring substances in the environment is verified, it is essential to treat the matrices that contain them. To do that, different types of treatment have been used in order to remedy this problem, but the physical, chemical and biological processes commonly employed in wastewater treatment plants (WWTP) have been shown to be inefficient in the degradation of colored effluent (Ananthashankar et al, 2014).

Among the treatments that have been used to try to minimize the pollution of water bodies by textile dyes are the advanced oxidation processes (AOPs) (Holanda et al. 2015). Among the most used AOPs are the Fenton processes (whose basic mechanism consists in the coagulation and oxidation of organic compounds) (Islam et al. 2019); photo-Fenton process, which makes use of Fenton reagents (iron ions and $\mathrm{H}_{2} \mathrm{O}_{2}$ ) with a source of radiation (usually ultraviolet or solar). The photo-peroxidation, in which the generation of hydroxyl radicals is potentiated by the combination of the 
oxidizing agent with a light radiation and the heterogeneous photocatalysis, in which a solid semiconductor catalyst is used, like $\mathrm{TiO}_{2}, \mathrm{ZnO}, \mathrm{Fe}_{2} \mathrm{O}_{3}, \mathrm{SiO}_{2}, \mathrm{Al}_{2} \mathrm{O}_{3}$ and $\mathrm{V}_{2} \mathrm{O}_{5}$ ( $\mathrm{Araújo}$ et al. 2016; Santos et al. 2018).

To apply the AOPs as a treatment for the degradation of persistent organic pollutants, it is necessary, initially, to optimize the conditions of the chosen process, considering the variables involved. In this context the factorial design technique has been used, aiming to find the "ideal" conditions for each situation (Barros Neto et al. 2010).

After using techniques that help to determine the favorable conditions to promote the degradation of pollutants, it is important to study the reaction kinetics under these conditions, in order to understand the behavior of the process. In general, the degradation by AOPs follows simple pseudo-first order models (Araújo et al. 2016). Therefore, alongside with these, it is important to evaluate the data set using new modeling, that are able to predict the percentage of degradation of the compounds as a function of the behavior of the variables involved in the process.

For modeling the dye degradation, predictive methods using artificial intelligence have been employed, given the low flexibility of statistical models in the face of complex data (Ghaedia et al., 2019). Therefore, artificial neural networks (ANNs) have been successfully applied due to their simplicity, robustness, reliability and non-linearity. An ANN is composed of parallel-connected computing units, which are inspired by biological neurons capable of solving multidimensional problems without any previous assumption (Ghaedi and Vafaei, 2017).

In addition, when applying treatments via AOP, it is necessary to evaluate the toxicity of the sample before and after the degradation process, since there are a large number of pollutants that have carcinogenicity, as well as allergenic effects, such as the dyes. After the treatment, the formation of intermediates that are more toxic than the original compounds must be considered, being necessary to carry out toxicity tests on different organisms, such as seeds, micro-crustaceans and bacteria (Bortoti et al. 2016; Sá et al. 2016; Charamba et al. 2018). 
Considering the above, this work evaluated the degradation of a mixture of the three dyes, direct red 23 (DR23), direct red 227 (DR227) and direct orange 26 (DO26) using homogeneous and heterogeneous advanced oxidation processes, employing bench reactors with UV-C and sunlight radiation. For this, the variables evaluated were the concentration of hydrogen peroxide $\left[\mathrm{H}_{2} \mathrm{O}_{2}\right]$, the iron concentration [Fe] and pHinitial $\left(\mathrm{pH}_{\mathrm{i}}\right)$, as well as a kinetic study to identify the adequacy of the experimental data to existing kinetic models. Then, an evaluation of the toxicity of the dye solution was carried out before and after submission to the most efficient AOP treatment, using seeds, bacteria and microcrustacean.

\section{MATERIALS AND METHODS}

The matrix employed in this study consisted of an aqueous solution containing a mixture of direct red DR23, DR227 and DO26, delivered by Nossa Senhora do Carmo laundry, Caruaru-PE. The characteristic wavelengths of the mixture of three dyes $(\lambda)$ monitored in this study and obtained by ultraviolet-visible spectrophotometry (UV/Vis) (Thermoscientific, Genesys 10S model); for which analytical curves were constructed in the concentration ranges from 0.1 to $2.0 \mathrm{mg}^{-\mathrm{L}^{-1}}$ and from 2.0 to $100.0 \mathrm{mg} . \mathrm{L}^{-1}$. These $\lambda$ had no displacement as a function of the initial $\mathrm{pH}$ of the solution $\left(\mathrm{pH}_{i}\right)$ studied $(3.5,4.5$ and 5.5). It is noteworthy that these dyes are amongst the most used ones in the dyeing of children's clothing.

\subsection{Preliminary Study: Homogeneous and Heterogeneous Processes}

Throughout the degradation study, an aqueous working solution containing the three-dye mixture was prepared in a concentration of $10 \mathrm{mg} \cdot \mathrm{L}^{-1}$ of each. Initially, 50 $\mathrm{mL}$ (surface area $13.85 \mathrm{~cm}^{2}$ ) of the working solution were placed in beakers and subjected to degradation assays for $60 \mathrm{~min}$.

The assays for the homogeneous processes (direct photolysis and the advanced oxidation processes (AOPs) photo-peroxidation, Fenton and photo-Fenton) were performed under the following conditions: hydrogen peroxide concentration $\left(\left[\mathrm{H}_{2} \mathrm{O}_{2}\right]\right)$ of 
$50 \mathrm{mg} \cdot \mathrm{L}^{-1}, \mathrm{pH}_{\mathrm{i}}$ of 5.5 (natural solution) and, whenever necessary, iron concentration ([Fe]) of $5 \mathrm{mg} \cdot \mathrm{L}^{-1}$. The iron catalyzed assays used as source of this reagent the ferrous sulfate heptahydrate $\left(\mathrm{FeSO}_{4} .7 \mathrm{H}_{2} \mathrm{O}\right.$, Química Moderna) and those in which oxidizing agent was used, employed $\mathrm{H}_{2} \mathrm{O}_{2}$ (30\% v/v, F Maia). The choice of variable values was made based on studies conducted by the research group in the Laboratório de Engenharia Ambiental e da Qualidade from the Universidade Federal de Pernambuco.

The heterogeneous processes $\left(\mathrm{TiO}_{2} / \mathrm{hu}, \mathrm{TiO}_{2}-\mathrm{Fe}^{2+} / \mathrm{hu}, \mathrm{TiO}_{2} / \mathrm{H}_{2} \mathrm{O}_{2} / \mathrm{hu}\right.$ and $\mathrm{TiO}_{2}-$ $\mathrm{Fe}^{2+} / \mathrm{H}_{2} \mathrm{O}_{2} / \mathrm{hu}$ ) were performed using a titanium dioxide concentration $\left(\left[\mathrm{TiO} \mathrm{O}_{2}\right]\right)$ of 300 mg. $\mathrm{L}^{-1}$ (Dinâmica) and $p \mathrm{H}_{i}$ of 3.5 (adjusted with $\mathrm{H}_{2} \mathrm{SO}_{4}, 0.1 \mathrm{M}$ ). The tests using iron, employed a concentration of 1 mg.L-1 of this metal; while the use of $\mathrm{H}_{2} \mathrm{O}_{2}$ was carried out at a concentration of $40 \mathrm{mg} \cdot \mathrm{L}^{-1}$ of said oxidant.

For both types of treatments (homogeneous and heterogeneous), bench reactors coated with aluminum foil were used, employing sunlight (Santana et al. 2017) and UV-C radiations (Zaidan et al. 2017). The first one with photo emission of 13.86 W. $\mathrm{cm}^{-2}$ in the visible range, $7.8 \times 10^{-2} \mathrm{~W} . \mathrm{cm}^{-2}$ in the UV-A/UV-B range and $9.8 \times 10^{-4}$ W. $\mathrm{cm}^{-2}$ in the UV-C range; and the second one with $1.98 \times 10^{-3} \mathrm{~W} . \mathrm{cm}^{-2}$.

\subsection{Factorial Design}

After selecting the AOP that presented the best percentages of degradation, the working conditions were defined using a factorial design $2^{3}$ with a central point in triplicate, totaling 11 experiments. The variables and levels studied were hydrogen peroxide concentration $\left(\left[\mathrm{H}_{2} \mathrm{O}_{2}\right]\left(100,150\right.\right.$ and $\left.\left.200 \mathrm{mg} \cdot \mathrm{L}^{-1}\right)\right)$, iron concentration ([Fe] $(1,3$ and 5 mg. $\left.\left.\mathrm{L}^{-1}\right)\right)$ and initial $\mathrm{pH}$ of the solution $\left(\mathrm{pH}_{i}(3.5 ; 4.5\right.$ and 5.5$\left.)\right)$.

\subsection{Study of the Hydrogen Peroxide Concentration Effect}

Based on the results of the factorial design and to optimize the $\mathrm{H}_{2} \mathrm{O}_{2}$ concentration used in the treatment of the dye mixture, a univariate study of this variable was carried out. Therefore, $50 \mathrm{~mL}$ of the working solution was submitted to the most efficient AOP, for a period of $60 \mathrm{~min}$, with the $\left[\mathrm{H}_{2} \mathrm{O}_{2}\right]$ studied being $40,50,60$, 
$70,80,90,100,150$ and $200 \mathrm{mg} . \mathrm{L}^{-1}$. The values of $[\mathrm{Fe}]$ and $p H_{i}$ were fixed based on the factorial design data.

\subsection{Evaluation of Degradation Kinetics and Determination of Residual $\mathrm{H}_{2} \mathrm{O}_{2}$}

In this stage of the study, the influence of the surface-volume relationship of the dye solution on the degradation efficiency was evaluated. For this purpose, a $1 \mathrm{~L}$ volume (surface area $400 \mathrm{~cm}^{2}$ ) of the dye mixture was treated using the most efficient AOP system, under the best working conditions.

The same procedure was repeated to evaluate the reaction kinetics. Thus, 10 $\mathrm{mL}$ aliquots were withdrawn at regular time intervals: $20,30,40,50,60,80,90,120$, 150 and $180 \mathrm{~min}$. After the experimental data were obtained, an adjustment was made to the pseudo-first order non-linear kinetic model proposed by Chan and Chu (2003). In addition, in order to monitor the possible intermediates formed during the reaction, aliquots of the dye solution were removed at 0, 30, 60, 90, 120, 150 and 180 min and subjected to a spectral scan analysis in the range of 190 at $600 \mathrm{~nm}$.

Finally, after degradation of the dye solution in the total time of $180 \mathrm{~min}$, the final sample was evaluated for the concentration of the residual hydrogen peroxide. For this, the colorimetric method was used, with test strips MQuant Test Peroxides (Merck), with a range of $\left[\mathrm{H}_{2} \mathrm{O}_{2}\right]$ from 0 to $25 \mathrm{mg} \cdot \mathrm{L}^{-1}$

\subsection{Mathematical Modeling Using Artificial Neural Networks}

The modeling of the experimental data was performed using artificial neural networks (ANNs) using Statistica software (Version 8.0). The networks used were of the Multilayer Percepton type (MLP) with the training algorithm based on the methods of Broyden, Fletcher, Goldfarb and Shanno (BFGS). The selected inputs were the variables: time, $\left[\mathrm{H}_{2} \mathrm{O}_{2}\right],[\mathrm{Fe}], \mathrm{pH}_{i}$ and $\left[\mathrm{TiO}_{2}\right]$ (heterogeneous process) and time, $\left[\mathrm{H}_{2} \mathrm{O}_{2}\right],[\mathrm{Fe}]$ and $\mathrm{pH}_{i}$ (homogeneous process). The selected output was the degradation of the dyes in the $\lambda$ studied $(240,306$ and $511 \mathrm{~nm})$. The sampling method used was randomized with data divided into $70 \%$ for training, $15 \%$ for test and $15 \%$ for validation. The ANNs were trained using 200 iterations and 10 replicates, totalizing 2000 iterations 
executed. The activation functions identity, logistic, hyperbolic, exponential, sine and tanh were chosen for the neurons used. The best results were based on the highest values of the linear regression coefficient $\left(R^{2}\right)$ of the training, the test and the validation; as well as the smaller errors obtained.

\subsection{Toxicity}

The toxicity tests were carried out under the same conditions of the kinetic study, before and after the submission of the dye mixture to the AOP for $180 \mathrm{~min}$. In the tests using seeds, the following species were used: Eruca sativa (arugula), Cichorium intybus (bitter chicory) Ocimum basilicum (basil) and Brassica juncea (mustard). For the evaluation of bacteriological toxicity, strains of Escherichia coli UFPE/DA and Proteus mirabilis UFPE/DA767 were used. In addition, the microcrustacean Artemia salina was also used.

The toxicity evaluation using seeds consisted of exposing them to the dye mixture before and after treatment; having as a negative control distilled water and as positive control a boric acid solution. The analyzes were performed in triplicate according to the methodology described by Zaidan et al. (2017). The results of the relative growth index $(R G /)$ and the germination index $(G /)$ were evaluated according to Young et al. (2012).

For the bacteriological toxicity experiments, the Mueller Hinton Agar medium (MHA) was used, overnight, at $36^{\circ} \mathrm{C}$, to cultivate the strains of the aforementioned bacteria, according to methodology described by Santana et al. (2018). The assays were performed in triplicate with the before and after treatment dye mixtures, without dilution and at dilutions of 1:10, 1:100, 1:500 and 1:1000.

For the tests using the microcrustacean Artemia salina, $25 \mathrm{mg}$ of eggs were placed in a vessel with sea water at pH 8.0 and temperature between 25 and $30^{\circ} \mathrm{C}$ for $48 \mathrm{~h}$, under aeration, until hatching. After that, Artemia salina eggs were collected for toxicity analysis. Then, the dye solutions before and after treatment with the AOP were placed in contact with 10 units of these microcrustaceans for a period of $24 \mathrm{~h}$. The tests were performed with $100 \%$ and $50 \%$ samples and diluted with sea water; 
which was used as a negative control. The experiments were performed in quadruplicate. After $24 \mathrm{~h}$, the survival of microcrustaceans was evaluated by counting the number of individuals that remained alive.

In addition to this evaluation, the toxicities of the residual hydrogen peroxide and iron were also evaluated. These additional tests were performed using two solutions separately: one containing iron at the concentration of $1.0 \mathrm{mg} . \mathrm{L}^{-1}$, because this was the value chosen in the factorial design, and another one containing $\mathrm{H}_{2} \mathrm{O}_{2}$ in the concentration of $0.25 \mathrm{mg} . \mathrm{L}^{-1}$ (chosen based on the residual amount of hydrogen peroxide).

\section{RESULTS AND DISCUSSION}

\subsection{Ultraviolet spectrophotometry analysis/visible}

Initially a spectral scan was performed, and then the presence or absence of wavelength shift was evaluated, considering the $\mathrm{pH}$ variation for the dye mixture analyzed. It was found that for the three ranges of $\lambda$ analyzed, three of the peaks did not suffer interference (Figure 1).

Figure 1 - Spectral scan of the dye mixture solution in different $\mathrm{pH}$

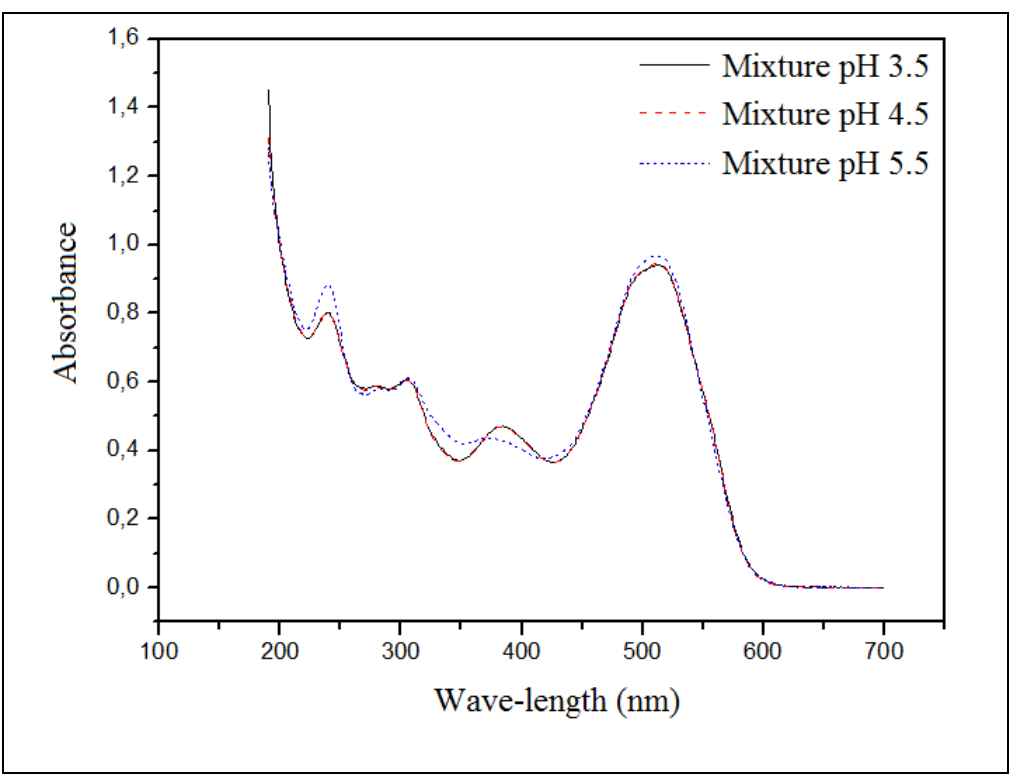


Analyzing Figure 1, it was chosen to monitor the wavelengths $(\lambda)$ of 240,306 and $511 \mathrm{~nm}$. The $240 \mathrm{~nm}$ value is assigned to the aromatic rings present in the dye molecules, being close to the values cited in the literature characteristic of aromatic compounds as described by Paulino; Araujo; Salgado (2015) and Prado and Godoy (2003). The $\lambda$ at 306 and $511 \mathrm{~nm}$ indicate the presence of chromophoric groups corresponding to orange and red colorations.

\subsection{Preliminary Study: Homogeneous and Heterogeneous Processes}

Aiming to determine the most efficient treatment to promote the degradation of the mixture of the three dyes under study, a preliminary test was carried out with the homogeneous processes (photolysis, photo-peroxidation, photo-Fenton and Fenton) and heterogeneous treatments $\left(\mathrm{TiO}_{2} ; \mathrm{TiO}_{2}-\mathrm{Fe}^{2+} ; \mathrm{TiO}_{2} / \mathrm{H}_{2} \mathrm{O}_{2}\right.$ and $\mathrm{TiO}_{2}-$ $\left.\mathrm{Fe}^{2+} / \mathrm{H}_{2} \mathrm{O}_{2}\right)$.

It was observed that the photolysis and photo-peroxidation processes were not able to degrade the solution containing the dyes under study. A similar result was obtained for the treatment with $\mathrm{TiO}_{2}$ and $\mathrm{TiO}_{2}-\mathrm{Fe}^{2+}$, using sunlight. It was also observed that these heterogeneous treatments using only the catalyst combined with UV-C radiation showed low degradation efficiency ( $<17 \%)$ for all $\lambda$ analyzed.

The Fenton, photo-Fenton, $\mathrm{TiO}_{2} / \mathrm{H}_{2} \mathrm{O}_{2}$ and $\mathrm{TiO}_{2}-\mathrm{Fe}^{2+} / \mathrm{H}_{2} \mathrm{O}_{2}$ processes were efficient to degrade the blend of dyes DR227, DR23 and DO26. The photo-Fenton process was the only one amongst them that presented a degradation percentage superior to $90 \%$, for $\lambda=511 \mathrm{~nm}$; with a highlight to sunlight radiation in which the treatment efficiency reached $98.75 \%$, for the $\lambda$ already mentioned. The wavelengths of 240 and $306 \mathrm{~nm}$ were degraded by $25.82 \%$ and $27.64 \%$ using UV-C radiation and $66.78 \%$ and $29.10 \%$ using sunlight radiation.

A similar result was obtained by Grcic et al. (2014), in which the photo-Fenton process was applied using a photo-reactor with quartz tube and mercury lamp for degradation of 5 commercial dyes. In this study the percentages of degradation varied between 45 and 99\%. Santana et al. (2017) tested the efficiency of the photo-Fenton process using sunlight radiation and obtained degradations of $98.3 \%$ for the reactive 
blue dye BF-5G and $99.1 \%$ for the azo dye remazol RB 133\% at wavelengths of 621 and $515 \mathrm{~nm}$, respectively. In order to evaluate the variables involved in the most efficient process, these were studied using a factorial design.

\subsection{Factorial Design}

The factorial design was elaborated in order to evaluate the influence of the variables $\left[\mathrm{H}_{2} \mathrm{O}_{2}\right],[\mathrm{Fe}]$ and $p \mathrm{H}_{i}$ in the degradation percentual of the dye mixture. In this study, three characteristic wavelengths $(240,306$ and $511 \mathrm{~nm})$ were monitored. For a better understanding of the data obtained, a statistical analysis was performed, in which the calculations of the main effects and interaction between the factors were obtained using Statistica 8.0 software, for $95 \%$ of confidence, at the levels studied. Thus, the Pareto charts, cube plots and response surface were constructed for each of the evaluated wavelengths (Figure 2).

Through the analyses of the Pareto charts it was found that both the main and the interaction effects were statistically significant, with 95\% confidence, for the $\lambda$ of 240 and $511 \mathrm{~nm}$. As for $\lambda$ equal to $306 \mathrm{~nm}$ only the main effects, [Fe], $p H_{i}$ and the interaction between them were significant. Since the variables can not be evaluated in isolation, cub plots were generated for the wavelengths of 240 and $511 \mathrm{~nm}$ and a response surface for $306 \mathrm{~nm}$.

When analyzing Figure 2(d), it can be observed that there was an average reduction in the degradation percentage for the wavelength of $240 \mathrm{~nm}$ when it went from the lowest to the highest level of the $[\mathrm{Fe}]$ and $\left[\mathrm{H}_{2} \mathrm{O}_{2}\right]$ variables. For the $\mathrm{pH}_{i}$, there was an average increase of only $4.5 \%$ when performing such variation. Figure 1 ( $f$ ) showed an average increase of only $0.5 \%$ on the degradation percentage of the monitored groups at $511 \mathrm{~nm}$ when it went from the lowest to the highest level of the $\left[\mathrm{H}_{2} \mathrm{O}_{2}\right]$ variable, there was also a reduction of less than $2.0 \%$ for the variables $[\mathrm{Fe}]$ and $\mathrm{pH}_{i}$. 
Figure 2 - Pareto charts for the degradation of the dye mixture in the $\lambda$ of (a) 240, (b) 306 and (c) $511 \mathrm{~nm}$; Cube plots and response surface for the $\lambda$ of: (d) $240 \mathrm{~nm}$, (e) 306 $\mathrm{nm}$ and (f) $511 \mathrm{~nm}$

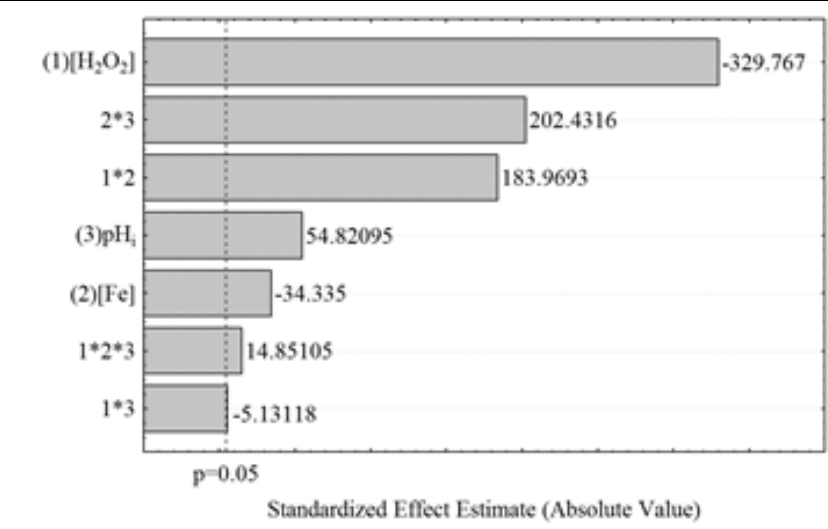

(a) $240 \mathrm{~nm}$

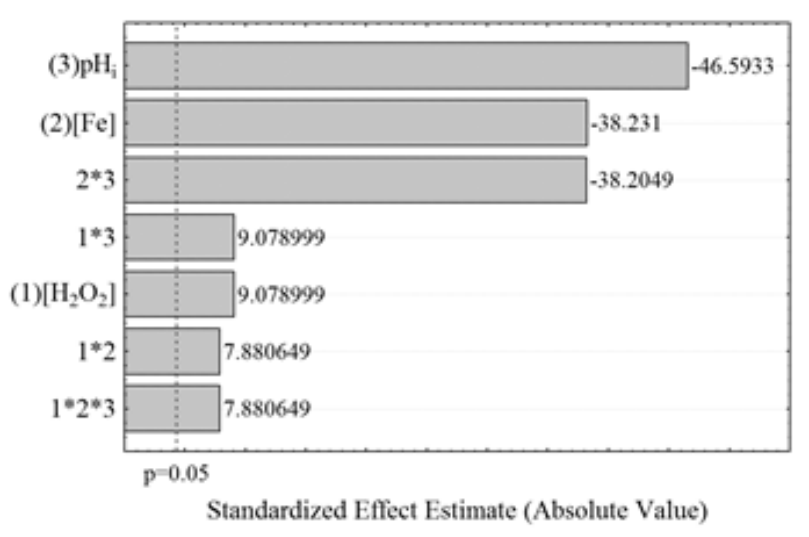

(c) $511 \mathrm{~nm}$

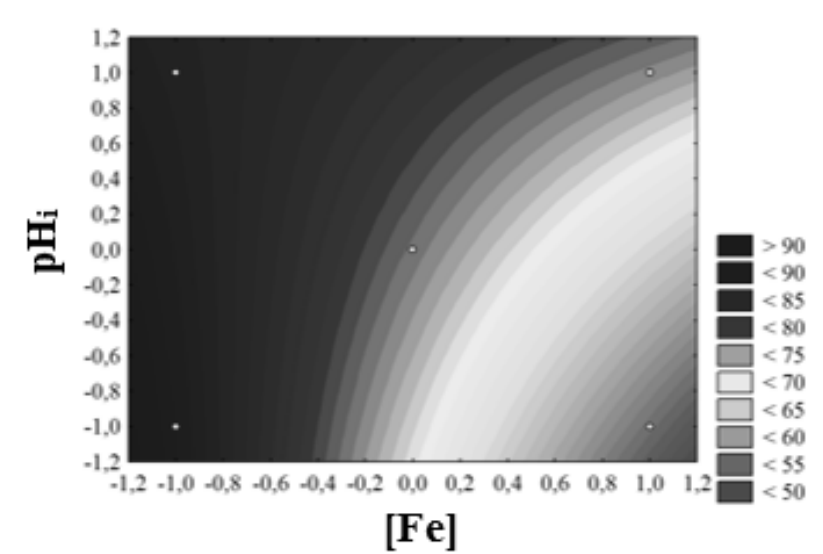

(e) $306 \mathrm{~nm}$

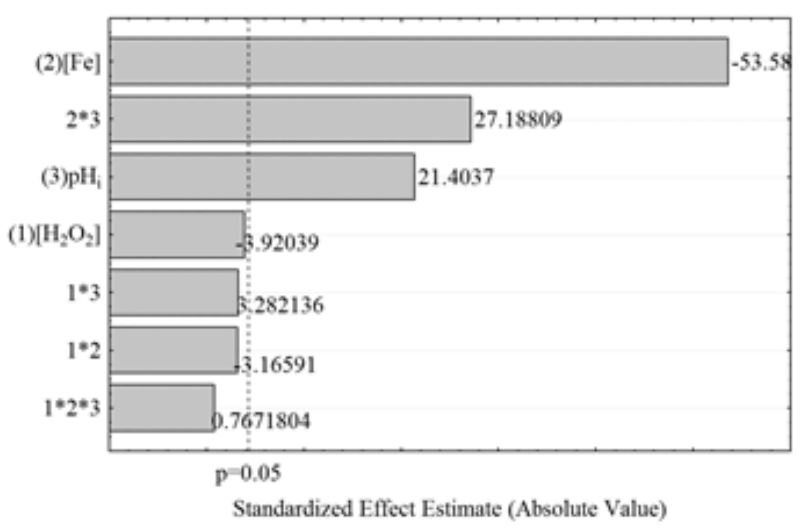

(b) $306 \mathrm{~nm}$

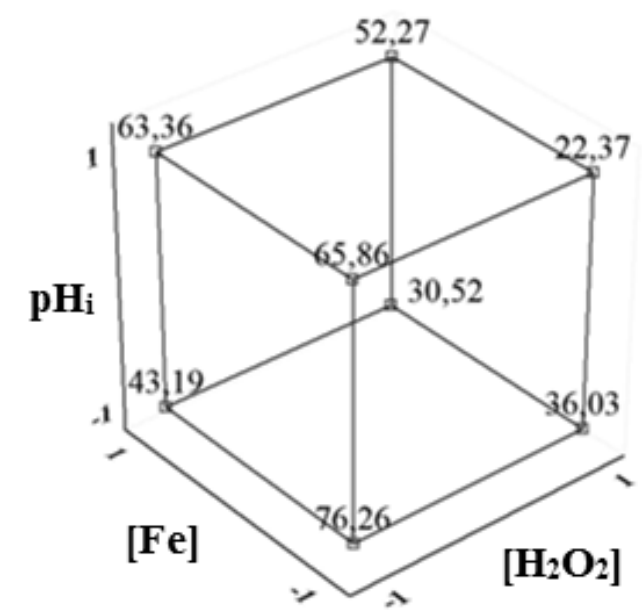

(d) $240 \mathrm{~nm}$

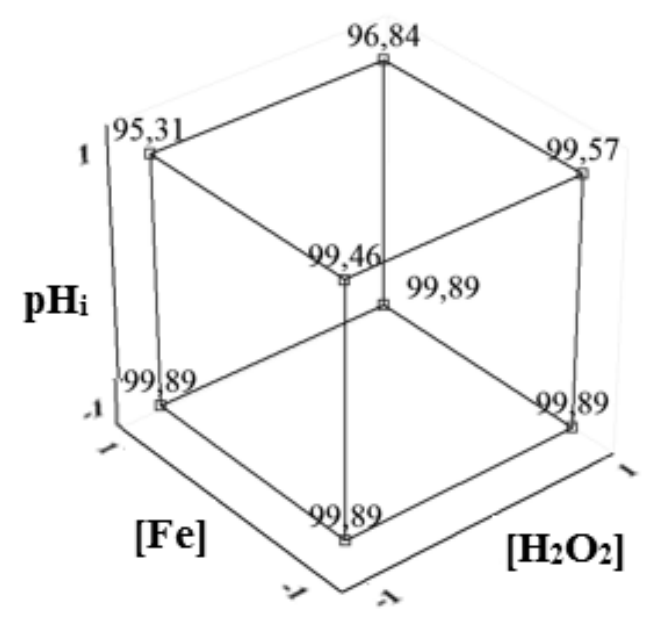

(f) $511 \mathrm{~nm}$ 
For $\lambda$ equal to $306 \mathrm{~nm}$, it was verified that the variation of the factor $\left[\mathrm{H}_{2} \mathrm{O}_{2}\right]$ was not significant, remaining only to evaluate the influence of the other variables. It was observed in Figure 2 (e) that the combination of the lower levels of $\mathrm{pH}_{i}$ and $[\mathrm{Fe}]$ studied resulted in a greater degradation of the three dyes mixture under study.

As the percentage differences on average were lower than 5\% and higher percentages of degradation were obtained when the lowest levels of the variables were applied, it was defined the use of $[\mathrm{Fe}]$ equal to $1 \mathrm{mg} \cdot \mathrm{L}^{-1}, \mathrm{pH}_{i}$ of 3.5 and the lowest value of $\left[\mathrm{H}_{2} \mathrm{O}_{2}\right]\left(100 \mathrm{mg} \cdot \mathrm{L}^{-1}\right)$.

These results are consistent with literature data, where it is possible to find works that mention the use of $\mathrm{pH}$ values below 4 to promote a greater efficiency of the photo-Fenton process in the removal of organic pollutants (Pouran et al. 2015; Ebrahiem et al. 2017). Chitra et al. (2012) verified in their study that the best pH range for the photo-Fenton/sunlight system is between 3-4; while Brito and Silva (2012) state that higher values of $\mathrm{pH}$ can cause the precipitation of ferric oxyhydroxides. Thus, in order to further improve the efficiency of the treatment employed, as well as to reduce the operational costs, a more detailed study of the hydrogen peroxide variable was conducted.

\subsection{Study of the Effect of Hydrogen Peroxide Concentration}

Mitre et al. (2012) state that in photo-Fenton processes it is of fundamental importance to evaluate more specifically the influence of $\mathrm{H}_{2} \mathrm{O}_{2}$ on the pollutant degradation. Thus, a study of the variation of $\left[\mathrm{H}_{2} \mathrm{O}_{2}\right]$ was carried out. It was verified that the degradation percentages did not present significant variations for the $\lambda$ of 511 and $306 \mathrm{~nm}$, with the results obtained being within the experimental error. However, when analyzing the wavelength of $240 \mathrm{~nm}$, characteristic of the presence of aromatic groups, it is possible to notice that greater degradations were achieved when using 80 mg. $\mathrm{L}^{-1}$ of $\mathrm{H}_{2} \mathrm{O}_{2}$. However, when performing a comparative analysis with the data found for concentrations of 40 and $50 \mathrm{mg} \cdot \mathrm{L}^{-1}$, $\mathrm{t}$ is observed that the differences between the percentages obtained are less than $1 \%$, thus not justifying using higher concentrations 
of the oxidizing agent. Therefore, it was decided to continue the studies using $\left[\mathrm{H}_{2} \mathrm{O}_{2}\right]$ of $40 \mathrm{mg} \cdot \mathrm{L}^{-1}$.

Santana et al. (2017) performed a similar study of the influence of $\left[\mathrm{H}_{2} \mathrm{O}_{2}\right]$ on the degradation of the reactive blue BF-5G and red remazol RB133\% dyes by Fenton process. The authors observed that for both dyes there was little change in degradation percentages (between $99.2 \%$ and 99.8\%) with the change in $\left[\mathrm{H}_{2} \mathrm{O}_{2}\right](40,60$, $80,100,120$ and $150 \mathrm{mg}^{-\mathrm{L}^{-1}}$ ), the results being within the limits of the experimental error.

\subsection{Evaluation of Degradation Kinetics}

Initially, before entering the actual kinetic evaluation, tests were carried out to verify if there is a significant influence of the ratio between the surface area and the volume of the treated solution in the degradation process. For that, [Fe] of $1 \mathrm{mg} . \mathrm{L}^{-1}$, $p H_{i}$ of 3.5 and $\left[\mathrm{H}_{2} \mathrm{O}_{2}\right]$ of $40 \mathrm{mg} \cdot \mathrm{L}^{-1}$ were used for $1000 \mathrm{~mL}$ of the dye mixture solution. It was found that by employing a larger volume of solution to be treated, higher percentages of degradation were obtained for the three monitored wavelengths. This fact indicates that the larger the available surface area for the volume of the solution to be treated, the greater the degradation efficiency. Because of that, since the depth of the solution region to be treated in the $1000 \mathrm{~mL}$ container is smaller and as in this treatment, the entire container has been irradiated, the process efficiency will be directly the depth of the medium. Thus, it was decided to perform the kinetic study using $1000 \mathrm{~mL}$ of the solution containing the dye mixture.

The kinetic monitoring of the photo-Fenton/sunlight process was carried out, with aliquots being removed over time. The data obtained with respect to the evolution of the concentration of the dye solution in the $\lambda$ were then treated and then a graph of the reaction kinetics was generated, verifying the fit to the model proposed by Chan and Chu (2003). 
Figure 3 - Kinetic evolution of the degradation of the dye mixture with adjustment to the model of Chan and Chu (2003), containing the conversion data and kinetic parameters

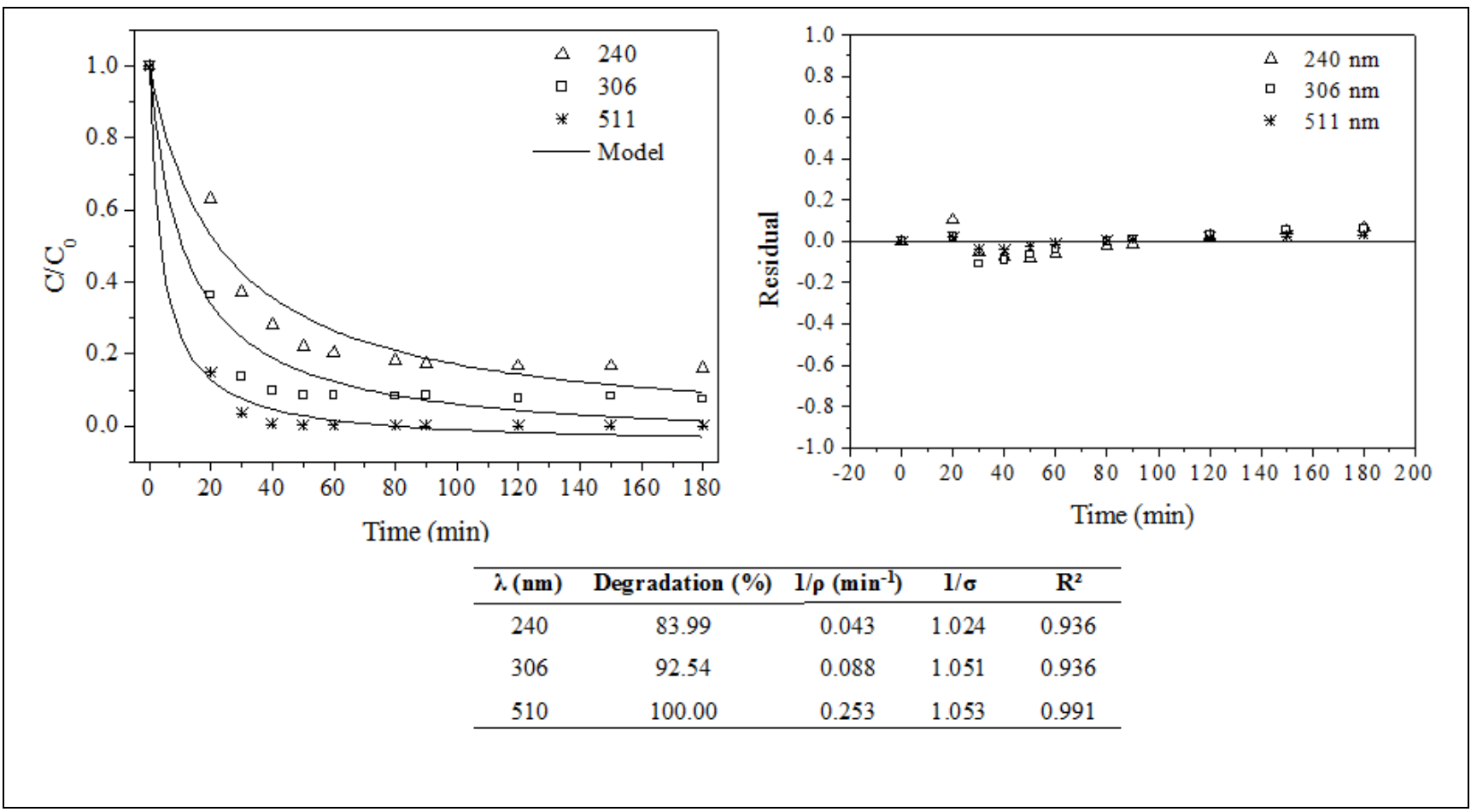

The analysis of Figure 3 shows a rapid degradation of the dye mixture in the monitored $\lambda$. This was because the concentration decay was very marked in the first $30 \min (86.24 \%$ for $\lambda=306 \mathrm{~nm}$ and $96.51 \%$ for $\lambda=511 \mathrm{~nm})$ and $77.94 \%$ after $50 \min$ for $\lambda=240 \mathrm{~nm}$. This fact was already expected in view of a higher resistance to the degradation of the aromatic groups present in this wavelength range.

A study by Nascimento et al. (2017) of the degradation of the Remazol goldyellow RNL-150\% and turquoise reactive Q-G125 dyes, using the same photoFenton/sunlight system, found that after 35 min, a higher degradation rate occurred, stabilizing after $75 \mathrm{~min}$. It was also found that after $85 \mathrm{~min}$, the dye degradation was greater than 95\% for all $\lambda$ monitored $(339,411,625$ and $661 \mathrm{~nm})$, except for $239 \mathrm{~nm}$, (aromatic groups), which was 82\%.

The residual data presented in Figure 3 confirm the good fit of the experimental data to the kinetic model of Chan and Chu (2003); for which significant linear regression coefficients (greater than 0.9) were obtained. According to Chan and Chu 
(2003), the higher the ratio $1 / \rho$, the higher the initial decrease in the concentration of the dye. Therefore, it can be stated that the oxidation capacity ( $\sigma$ ) and the decay in the concentration of the dyes for the $\lambda$ of 306 and $511 \mathrm{~nm}$ are higher than the value obtained for the $\lambda$ of $240 \mathrm{~nm}$, again showing that there is a greater difficulty in degrading it.

\subsection{Artificial Neural Network Modeling}

Among all the simulations performed through the software Statistica 8.0, it was verified that the RBF model was not precise for the analysis of homogeneous and heterogeneous processes data. Soon, the results were evaluated using the MLP model. For the homogeneous process it was verified that the best network was composed of nine neurons in the hidden layer (MLP 4-9-3) and $R^{2}$ values equal to $0.986 ; 0.952 ; 0.965$ for training, testing and validation, respectively. For the heterogeneous process the network was composed of six neurons in the hidden layer (MLP 5-6-3) and $\mathrm{R}^{2}$ values equal to $0.977 ; 0.992 ; 0.982$ for training, testing and validation, respectively. The function of activation of the input and output layers were Tahn and Tanh for both processes, with sum of squares (SOS) as function of error. The training algorithms were BFGS 103 for the homogeneous process and BFGS 119 for the heterogeneous process.

From the ANNs selected and using Statistica 8.0 software, the weights data of the studied layers (input, intermediate and output) were obtained. Once the weights were found, the relative importance (\%) of the input variables in each type of process was verified. In order to have a better understanding of this factor, graphs were generated containing the contribution of each factor (Figure 4).

When analyzing Figure 4, it can be seen that for the ANN obtained for the homogeneous processes the variable $\left[\mathrm{H}_{2} \mathrm{O}_{2}\right]$ presented a relative importance $(47.33 \%)$ well above the other input variables. While for the ANN obtained considering the heterogeneous treatment, the variables $\left[\mathrm{H}_{2} \mathrm{O}_{2}\right], \mathrm{pH}_{i}$ and $\left[\mathrm{TiO}_{2}\right]$ presented similar importance (around 20\%), with the [Fe] variable being the most significant of the analyzed variables. This result corroborates the decision made throughout the study 
that the homogeneous process leads to a greater degradation of the dye mixture under study, since $\mathrm{TiO}_{2}$ did not have a considerable influence on the other variables. Thus, the ANN model can be used to predict the percentage of degradation of the dyes under study, considering different from the input variables studied.

Figure 4 - Relative importance (\%) of input variables in process efficiency

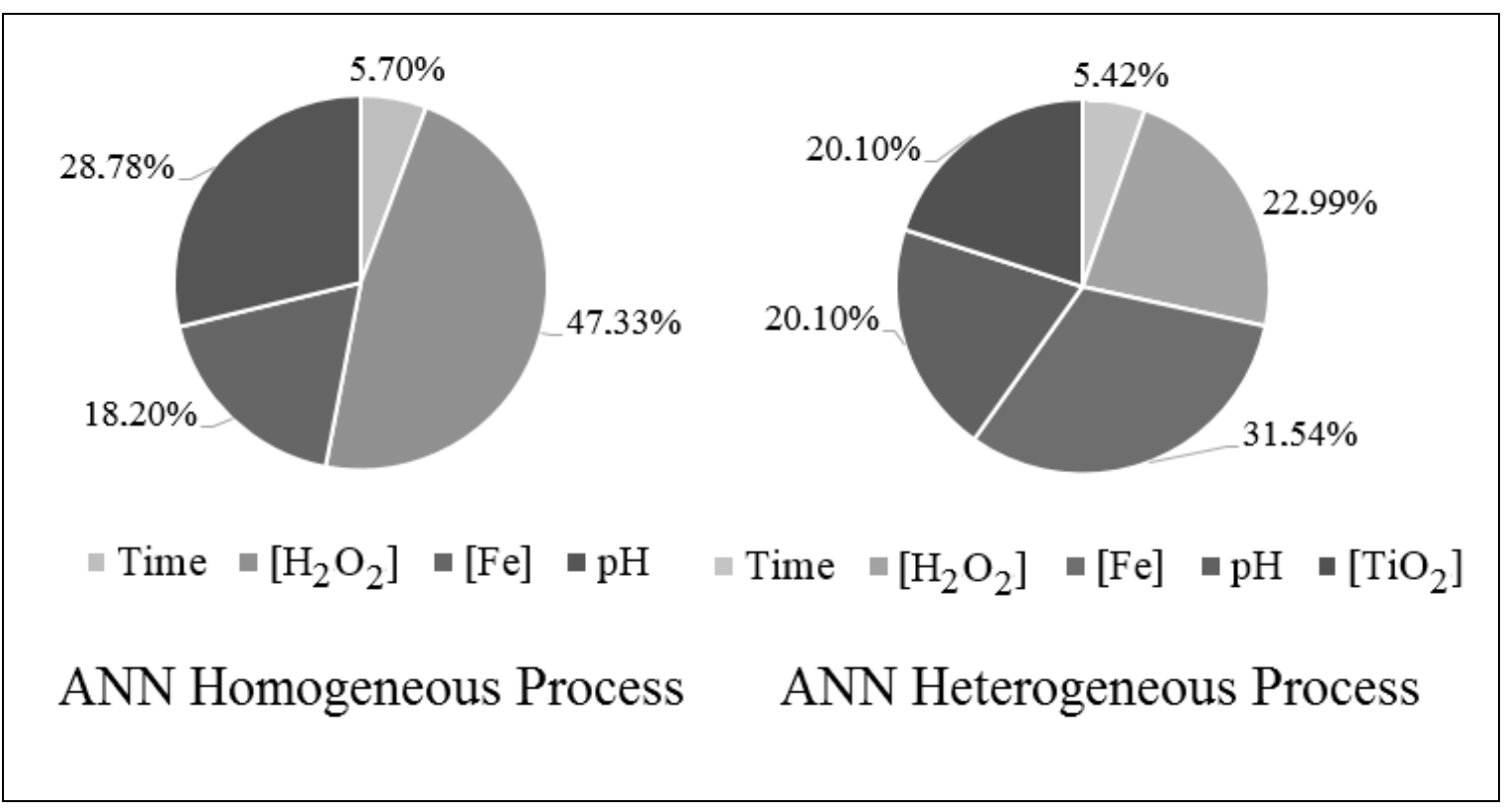

\subsection{Toxicity assessment}

The results obtained from the seed toxicity tests for the solution containing the dye mixture before and after treatment with the photo-Fenton/sunlight AOP are set forth in Figure 5. In this figure, it can be verified that for the species Eruca sativa and Ocimum basilicum, higher germination index $(G l)$ were obtained after treatment. As for the species Cichorium intybus and Brassica juncea, it showed that the before treatment solution (SBT) gave a higher Gl when compared to post-treatment solution (SPT). It was also verified that the root growth index $(R G /)$ for E. sativa, C. intybus and $O$. basilicum seeds was higher for the post-treatment solution, while no difference was observed between the SBT and SPT evaluated for the seeds of $B$. juncea. 
Figure 5 - Graphical analysis of the RGI and GI values for the studied seeds

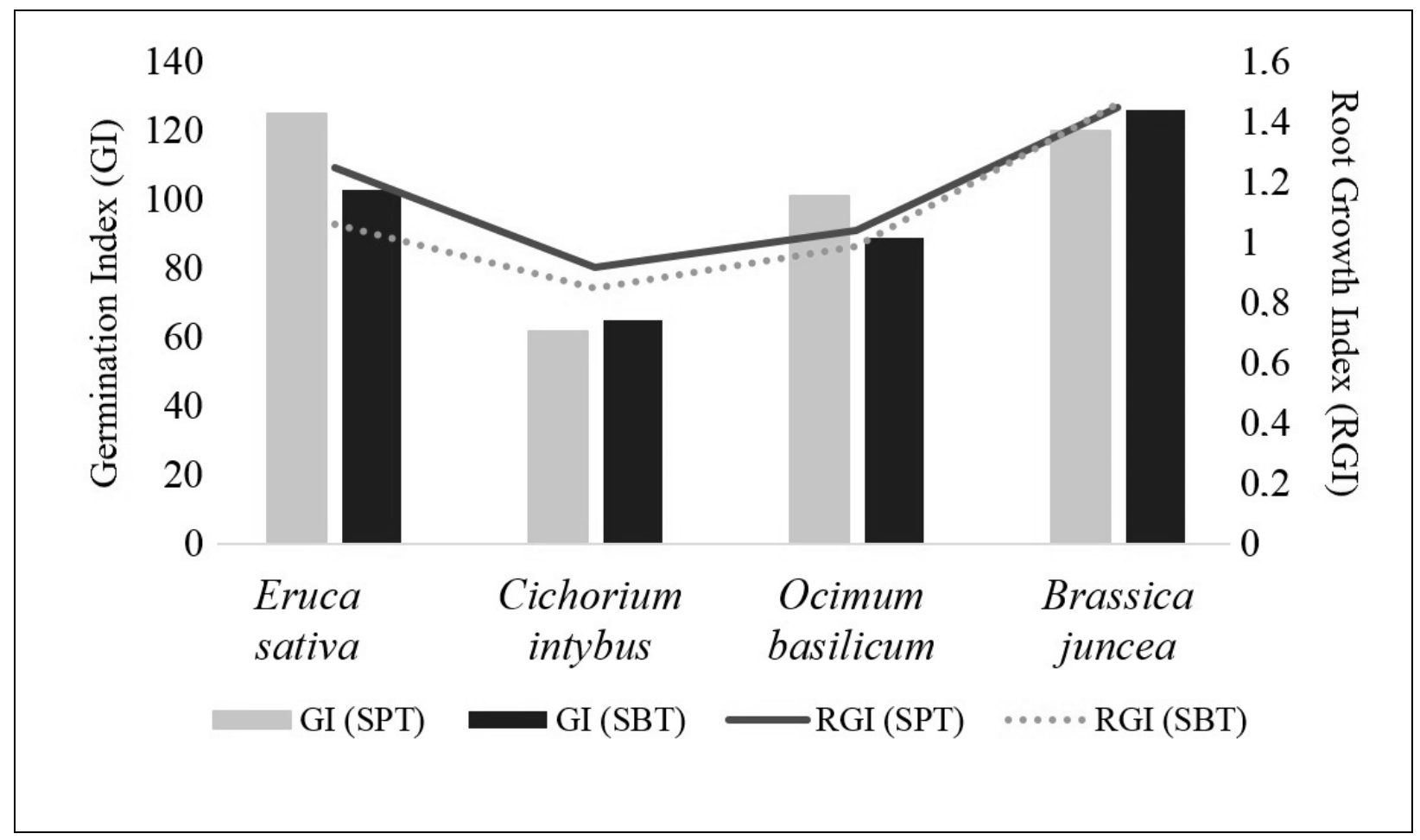

According to Young et al. (2012), the value of the $R G I$ is differentiated into three categories: a) $0<R G I<0.8$, indicating growth inhibition; b) $0.8<R G I<1.2$ reporting that the effect is not significant and c) $R G I>1.2$ showing that there was growth stimulation. Therefore, the mixture of the dyes before and after treatment did not present toxicity to the seeds tested, since all $R G /$ values were higher than 0.8 . Aiming to broaden the spectrum of organisms to evaluate the toxicity effect of the dye mixture, additional testing was performed with bacteria.

It was observed that the samples did not present toxicity to Escherichia coli strains both for SBT and SPT, at the different dilutions studied. For the Proteus mirabilis strains, it was verified that the SBT and SPT samples with and without dilution $(0.180 \pm 0.052 \leq \mathrm{OD} \leq 0.294 \pm 0.079)$ had $\mathrm{OD}$ values lower than those obtained for the negative control $(0.409 \pm 0.003)$, indicating a possible toxicity of the dye mixture studied for this type of bacteria.

In view of this result, another toxicity analysis was carried out using a third group of living organisms, microcrustaceans of the species Artemia salina. This group was chosen since these organisms are very sensitive to relatively toxic compounds. 
This assay involved the analysis of both SBT and SPT, as well as the reagents used in the process (iron and $\mathrm{H}_{2} \mathrm{O}_{2}$ ).

It was observed that dyes solution, when submitted to the treatment with the selected AOP, was toxic to the species under study, since no living individuals were observed. Then, the toxicity of the solution of $\mathrm{H}_{2} \mathrm{O}_{2}$ in its residual concentration $(0.25$ $\mathrm{mg} . \mathrm{L}^{-1}$ ) and iron (1 mg. $\left.\mathrm{L}^{-1}\right)$ was analyzed to verify if these were the cause for the total mortality of Artemia salina. It was also both reagents mentioned have toxicity to microcrustaceans, since the viability of the species was reduced. Thus, it can be affirmed that both the products resulting from the degradation of the dyes in the 180 min interval, as well as the iron and $\mathrm{H}_{2} \mathrm{O}_{2}$ present toxic effects on Artemia salina

\section{CONCLUSIONS}

The experimental data demonstrated the applicability of advanced oxidation processes for the degradation of the DR23, DR227 and DO26 dyes. The photo-Fenton process proved to be more efficient for the proposed objective, indicating that $\left[\mathrm{Fe}^{2+}\right]$ directly influences the degradation. Furthermore, it was confirmed the necessity of acidic $\mathrm{pH}$ for a better conduction of the reaction, which follow a pseudo-first order non-linear model. It was also possible to use a mathematical model with artificial neural networks of the Multilayer Percepton type to predict the percentages of degradation. The proposed treatment generated toxic products sensitive to the microcrustacean Artemia salina, a fact that did not occur when testing the bacteria Escherichia coli and Proteus mirabilis. The behavior of the seeds Eruca sativa, Ocimum basilicum Cichorium intybus and Brassica juncea showed variability when they were exposed to the treated solution. Demonstrating the necessity of the toxicity evaluation after treatment by AOPs, especially applying different types of organisms and their representations. 


\section{ACKNOWLEDGEMENTS}

To the NUQAAPE/FACEPE, to FADE/UFPE and to the Laboratório de Bioquímica de Proteínas of the Universidade Federal de Pernambuco for conducting the bacterial toxicity tests.

\section{REFERENCES}

ANANTHASHANKAR R, ALHATTAB M, RAMAKRISHNAN VV, GHALY AE. Production, characterization and treatment of textile effluents: A critical review. J. Chem. Eng. Process Technol. 2014;5(1):1-18.

ARAÚJO KS, ANTONELLI R, GAYDECZKA B, GRANATO AC, MALPASS GRP. Processos oxidativos avançados: uma revisão de fundamentos e aplicações no tratamento de águas residuais urbanas e efluentes industriais. Ambiente e Água. 2016;11(2):387-401.

BARROS NB, SCARMINIO IS, BRUNS RE. Como Fazer Experimentos: Pesquisa e desenvolvimento na ciência e na indústria. 4th ed. Unicamp, São Paulo; 2010.

BORTOTI AA, ROSA MF, BARICCATTI RA, LOBO VS. Avaliação do processo foto-Fenton na descoloração de um corante têxtil comercial. Semina: Ciências exatas e tecnológicas. 2016;37(1):81-90.

BRITO NND, SILVA VBM. Processos oxidativos avançados e sua aplicação ambiental. Rev. Eletron. de Eng. Civil. 2012;1(3):36-47.

CHAN KH, CHU W. Modeling the reaction kinetics of Fenton's process on the removal of atrazine. Chemosphere. 2003;51(4):305-311.

CHARAMBA LVC, SANTANA RMR, NASCIMENTO GE, CHARAMBA BVC, MOURA MC, COELHO LCBB, OLIVEIRA JGC, DUARTE MMMB, NAPOLEÃO DC. Application of the advanced oxidative process on the degradation of the green leaf and purple açaí food dyes with kinetic monitoring and artificial neural network modelling. Water Sci.

Technol. 2018; 78:1094-1103.

CHITRA S, PARAMASIVAN K, CHERALATHAN M, SINHA PK. Degradation of 1,4-dioxane using advanced oxidation processes. Environ. Sci. Pollut. Res. 2012;19(3):871-878.

EBRAHIEM EE, AL-MAGHRABI MN, MOBARKI AR. Removal of organic pollutants from industrial wastewater by applying photo-Fenton oxidation technology. Arab. J. Chem. 2017; 10:1674-1679. 
GHALY AE, ANANTHASHANKAR R, ALHATTAB M, RAMAKRISHNAN VV. Production, characterization and treatment of textile effluents: a critical review. J. Chem. Eng. Process Technol. 2014; 5:1-18.

GUARATINI CCI, ZANONI MVB. Corantes Têxteis. Quimica Nova. 2000;23(1):71-78.

HISAINDEE S, MEETANI MA, RAUF MA. Application of LC-MS to the analysis of advanced oxidation process (AOP) degradation of dye products and reaction mechanisms. Trends Analyt. Chem. 2013;49:31-44.

GRCIC I, PAPIC S, MESEC D, KOPRIVANAC N, VUJEVIC D. The kinetics and efficiency of UV assisted advanced oxidation of various types of commercial organic dyes in water. J. Photochem. Photobiol. A. Chem. 2014;273:49-58.

HOLANDA CA, SOUZA JL, SANTOS CC, SILVA HAS, SANTANA SAA, COSTA MCP, SCHULTZ S, BEZERRA CWB. Remoção do Corante Têxtil Turquesa de Remazol Empregando Aguapé (Eichhornia crassipes) como adsorvente. Orbital - Electronic J. Chem. 2015;7(2):141-154.

ISLAM S, SHAIKH IA, FIRDOUS N, ALI A, SADAF Y. A new approach for the removal of unfixed dyes from reactive dyed cotton by Fenton oxidation. J. Water Reuse Desal. 2019;9(2):133-141.

MITRE TK, LEÃO MMD, ALVARENGA MCN. Tratamento de águas contaminadas por diesel/biodiesel utilizando processo Fenton. Eng. Sanit. Ambient. 2012;17(2):129-136.

NASCIMENTO GE, NAPOLEÃO DC, SANTANA RMR, CHARAMBA LVC, OLIVEIRA JGC, MOURA MC, COELHO LCBB, DUARTE MMMB. Degradation of textile dyes Remazol Yellow Gold and Reactive Turquoise: optimization, toxicity and modeling by artificial neural networks. Water Sci. Technol. 2018;(3):812-823.

PAULINO TRS, ARAÚJO RS, SALGADO BCB. Estudo de oxidação avançada de corantes básicos via reação Fenton ( $\left.\mathrm{Fe}^{2+} / \mathrm{H}_{2} \mathrm{O}_{2}\right)$. Eng. Sanit. Ambient. 2015;20(3):347-352.

PRADO MA, GODOY MT. Corantes Artificiais em Alimentos. Alim. Nutr. Araraquara. 2003;14(2):237-250.

POURAN SR, ABDUL AZIZ AR, WAN DAUD WMA. Review on the advances in photoFenton oxidation system for recalcitrant wastewaters. J. Ind. Eng. Chem. 2015; 21:5369.

RAWAT D, SHARMA RS, KARMAKAR S, ARORA LS, MISHRA V. Ecotoxic potential of a presumably non-toxic azo dye. Ecotox. and Environ. Safe. 2018; 148:528-537.

SÁ JLF, SIQUEIRA WN, SILVA HAMF, SANTOS MLO, SANTOS FTJ, SILVA LRS, CABRAL DLV, BEZERRA ICF, SOARES LAL, MELO AMMA. Evaluation of molluscicidal activity of 
Anadenanthera colubrina extracts on adult mollusc and embryos of the species Biomphalaria glabrata (Say, 1818). Scientia Plena. 2016;12(10):1-9.

SANTANA RMR, NASCIMENTO GE, NAPOLEÃO DC, DUARTE MMB. Degradation and kinetic study of Reactive blue BF-5G and Remazol red RB 133\% dyes using Fenton and photo-Fenton process. REGET. 2018;21(2):104-118.

SANTANA RMR, NASCIMENTO GE, SILVA PKA, LUCENA ALA, PROCÓPIO TF, NAPOLEÃO TH, DUARTE MMMB, NAPOLEÃO DC. Kinetic and ecotoxicological evaluation of the direct orange 26 dye degradation by Fenton and solar photo-Fenton processes. REGET. 2018;22(5):1-20.

SANTOS MMM, DUARTE MMMB, NASCIMENTO GE, SOUZA NBG, ROCHA ORS. Use of $\mathrm{TiO}_{2}$ photocatalyst supported on residues of polystyrene packaging and its applicability on the removal of food dyes. Environ. Technol. 2018;40(12):1494-1507.

YOUNG BJ, RIERA NI, BEILY ME, BRES PA, CRESPO DC, RONCO AE. Toxicity of the effluent from an anaerobic bioreactor treating cereal residues on Lactuca sativa. Ecotox. Environ. Safe. 2012;76(2):182-186.

ZAIDAN LEMC, PINHEIRO RB, SANTANA RMR, CHARAMBA LVC, NAPOLEÃO DC, SILVA VL. Evaluation of efficiency of advanced oxidative process in degradation of 2-4 dichlorophenol employing UV-C radiation reator. REGET;21(2):147-157. 